\title{
Severe cytomegalovirus pneumonitis in HIV infected patients with higher than average CD4
}

\section{counts}

\author{
S B Squire, M C I Lipman, E K Bagdades, P M Mulvenna, J E Grundy, P D Griffiths, \\ M A Johnson
}

\begin{abstract}
Background Cytomegalovirus may replicate within the lungs both of recipients of transplants and of patients infected with the human immunodeficiency virus (HIV). A hypothesis formulated by this group was that a host damaging immune response might be provoked by cytomegalovirus infection and cause a severe pneumonitis in recipients of allogeneic transplants, whereas the progressive impairment of cellular immunity in patients with HIV disease would preclude a damaging immune response in the lungs, and thus protect these patients from severe cytomegalovirus pneumonitis. This study set out to discover whether severe cytomegalovirus pneumonitis arises in HIV infected patients.
\end{abstract}

Methods Data were prospectively collected on severity of pneumonitis and infectious agents identified in consecutive respiratory episodes in HIV infected patients undergoing diagnostic bronchoalveolar lavage during 20 months.

Results Eighty five episodes of pneumonitis occurred in 68 patients. Cytomegalovirus was identified as the only infectious agent in nine episodes (nine patients). Seven of the episodes were mild; all these patients had CD4 counts below $0.1 \times 10^{9} / 1$. The remaining two episodes were severe and ventilatory support was required. In both cases the CD4 counts were above $0.2 \times 10^{9} / 1$ and HIV infection appeared to have been acquired shortly before presentation.

Conclusion Although rare, severe cytomegalovirus pneumonitis may occur in HIV infected patients. Both patients with severe pneumonitis in this series had relatively well preserved immune function. These findings support the hypothesis that severe cytomegalovirus pneumonitis is an immunopathological condition.

We have suggested that cytomegalovirus pneumonitis requires the presence of cytomegalovirus in the lungs and a cellular host immune response. ${ }^{\prime}$ As patients with human immunodeficiency virus (HIV) disease have substantial and progressive impairment of cellular immunity, we predicted that cyto- megalovirus pneumonitis would not be a clinical problem unless immune function was restored by treatment. ${ }^{1}$ We therefore adopted the policy of regarding identification of cytomegalovirus at diagnostic bronchoalveolar lavage in HIV infected patients as not being in itself an indication for specific anticytomegalovirus treatment. Further support for this policy has come from reports that cytomegalovirus is not associated with increased mortality or morbidity when identified in the lungs of HIV infected patients with pneumonitis. ${ }^{2-5}$ To test our hypothesis and monitor our policy a prospective collection of data on the severity of all episodes of pneumonitis in HIV infected individuals was undertaken. We report on the episodes that occurred during 20 months in which cytomegalovirus was the only infectious agent identified at bronchoalveolar lavage.

\section{Methods}

Data on peripheral blood CD4 counts, treatment received, and infectious agents identified at bronchoalveolar lavage were collected prospectively during consecutive episodes of pneumonitis in HIV infected patients over 20 months from April 1989. The episodes were graded 1 to 12 for severity according to the criteria in table 1 . All bronchoalveolar lavage specimens were tested for bacteria, fungi, and mycobacteria by conventional microbiological techniques, for cytomegalovirus by detection of early antigen fluorescent foci (DEAFF) and cell culture, ${ }^{6}$ and for Pneumocystis carinii by Grocott and Papanicolau staining of cytospin

Table 1 Criteria for ranking severity of respiratory episodes

\begin{tabular}{lc}
\hline & Score \\
\hline Fever $\geqslant 38^{\circ} \mathrm{C}$ before lavage & 1 \\
Percutaneous capillary oxygen saturation: & \\
$\geqslant 95 \%$ before lavage and desaturation on exertion & 1 \\
$90-94 \%$ & 2 \\
$85-89 \%$ & 3 \\
$<85 \%$ or requiring oxygen therapy & 4 \\
Chest radiograph shadowing: & 1 \\
One zonc & 2 \\
Two zones & 3 \\
Three zones or confluent or generalised & 2 \\
Requiring ventilatory support & \\
Death from respiratory episode (maximum & 12 \\
scorc)
\end{tabular}


preparations. Cytospin preparations were also examined for viral inclusion bodies. Where possible blood and saliva were collected at the time of bronchoalveolar lavage for DEAFF testing and cell culture. All patients had detectable HIV-1 antibodies according to Wellcome enzyme immunoassay (Wellcome Diagnostics), which was confirmed by two other immunoassays. CD4 cell counting was carried out as described. ${ }^{7}$

\section{Results}

The frequency of identification of cytomegalovirus and Pneumocystis carinii in relation to severity of respiratory episode and peripheral blood CD4 count is given in table 2 . Eighty five episodes occurred in 68 patients. Cytomegalovirus was identified as the only infectious agent in nine episodes (nine patients)-see table 3. The severity ranking was less than 5 (median 2) in seven of these; CD4 counts were below $0.1 \times 10^{9} / 1$ (median $\left.0.013 \times 10^{9} / 1\right)$ in all seven at the time of bronchoalveolar lavage and the counts fell subsequently. None of these patients was given specific anticytomegalovirus treatment and all survived the pneumonitis. The remaining two episodes had severity grade 9 and 10 and both patients required ventilatory support and specific anticytomegalovirus treatment. In both cases $\mathrm{CD} 4$ counts were above 0.2 $\times 10^{9} / 1$ at the time of the pneumonitis and the levels rose subsequently. Further details of these two cases are given below.

CASE 1

Recurrence of dyspnoea, fever, and cough prompted the readmission in January 1990 of a 33 year old patient with newly diagnosed
AIDS. Three days previously he had been discharged after his first clinical presentation with a respiratory episode, in which Pneumocystis carinii and cytomegalovirus (DEAFF positive, culture positive, no viral inclusion bodies) had been identified at bronchoalveolar lavage and which had responded to a three week course of co-trimoxazole ( $120 \mathrm{mg} / \mathrm{kg}$ daily). Zidovudine ( $250 \mathrm{mg}$ six hourly) had been started 10 days earlier and he had received one $300 \mathrm{mg}$ dose of aerosolised pentamidine five days previously. On readmission a chest radiograph showed widespread interstitial shadowing (fig 1) and arterial blood gas analysis severe hypoxaemia. Endotracheal intubation and ventilation were required for 25 days and cytomegalovirus was the only infectious agent identified by bronchoalveolar lavage on two occasions during the first week of ventilation (DEAFF negative, culture positive, and viral inclusion body positive on both occasions). No infectious agents were identified in two subsequent lavages in the second and third weeks of ventilation. He received the following treatment for 28 days: intravenous ganciclovir (250 mg 12 hourly), immunoglobulin (Gammimmune) $77.5 \mathrm{~g}$ fortnightly, co-trimoxazole $120 \mathrm{mg} / \mathrm{kg}$ daily, and hydrocortisone $200 \mathrm{mg}$ six hourly. Zidovudine ( $250 \mathrm{mg}$ six hourly) and aerosolised pentamidine ( $300 \mathrm{mg}$ fortnightly) were reintroduced on day 28 . At discharge after two months the peripheral blood CD4 count was $0.378 \times 10^{9} / 1$. He returned to wcrk after a month (CD4 count $0.375 \times 10^{9} / 1$ ) and 15 months later remains well and in full time employment. The patient said that the only occasion he had been at risk of acquiring HIV was six weeks before his first admission; this had been followed two weeks later by fever, general

Table 2 Characteristics of the episodes in the study

\begin{tabular}{|c|c|c|c|c|}
\hline & $n$ & $\begin{array}{l}\text { No }(\%) \text { with } \\
\text { Pneumocystis carinii }\end{array}$ & $\begin{array}{l}\text { Median peripheral } \\
\text { blood CD4 count } \\
\left(\times 10^{9} / l\right)\end{array}$ & $\begin{array}{l}\text { Median severity } \\
\text { of episode }{ }^{\star}\end{array}$ \\
\hline Total & 85 & $29 \quad(34)$ & 0.042 & 4 \\
\hline Cytomegalovirus not identified & 63 & $19(30)$ & 0.05 & 4 \\
\hline $\begin{array}{l}\text { Cytomegalovirus with other infectious } \\
\text { agent } \\
\text { Cytomegalovirus alone }\end{array}$ & $\begin{array}{r}13 \\
9\end{array}$ & $\begin{array}{ll}9 & (69) \\
0 & \end{array}$ & $\begin{array}{l}0.011 \\
0.02\end{array}$ & $\begin{array}{l}6 \\
4\end{array}$ \\
\hline
\end{tabular}

$\star$ See table 1.

Table 3 Characteristics of patients with cytomegalovirus pneumonitis

\begin{tabular}{|c|c|c|c|c|c|c|c|c|c|c|c|}
\hline \multirow[b]{2}{*}{$\begin{array}{l}\text { Patient } \\
\text { No }\end{array}$} & \multirow[b]{2}{*}{$\operatorname{Sex}$} & \multirow[b]{2}{*}{$\begin{array}{l}\text { Age } \\
(y)\end{array}$} & \multirow{2}{*}{$\begin{array}{l}\text { CD4 count } \\
\left(\times 10^{9} / l\right) \text { at } \\
\text { time of } \\
\text { pneumonitis }\end{array}$} & \multirow{2}{*}{$\begin{array}{l}\text { Severity } \\
\text { of } \\
\text { pneumonitis }\end{array}$} & \multicolumn{3}{|c|}{ Bronchoalveolar lavage findings } & \multicolumn{2}{|l|}{ Saliva } & \multicolumn{2}{|l|}{ Blood } \\
\hline & & & & & $\begin{array}{l}\text { Viral } \\
\text { inclusions }\end{array}$ & $D E A F F$ & $\begin{array}{l}\text { Cell } \\
\text { culture }\end{array}$ & $D E A F F$ & $\begin{array}{l}\text { Cell } \\
\text { culture }\end{array}$ & $D E A F F$ & $\begin{array}{l}\text { Cell } \\
\text { culture }\end{array}$ \\
\hline 1 & $\mathbf{M}$ & 33 & $0 \cdot 24$ & 10 & + & - & + & - & - & - & - \\
\hline 2 & $\mathbf{M}$ & 37 & $0 \cdot 23$ & 9 & - & - & + & - & - & - & - \\
\hline 3 & $\mathbf{M}$ & 42 & 0.08 & 2 & - & - & + & NA & NA & NA & NA \\
\hline 4 & $\mathbf{M}$ & 45 & 0.03 & 1 & - & + & - & + & - & + & - \\
\hline 5 & $\mathrm{~F}$ & 36 & 0.02 & 2 & + & + & + & NA & NA & NA & NA \\
\hline 6 & $\mathbf{M}$ & 37 & 0.01 & 4 & + & + & - & NA & NA & NA & NA \\
\hline 7 & $\mathbf{M}$ & 48 & 0.004 & 3 & - & + & - & NA & NA & NA & NA \\
\hline 8 & $\mathbf{M}$ & 27 & 0.001 & 4 & - & + & NA & - & - & - & - \\
\hline 9 & $\mathbf{M}$ & 26 & 0.001 & 2 & + & + & + & + & + & - & - \\
\hline
\end{tabular}




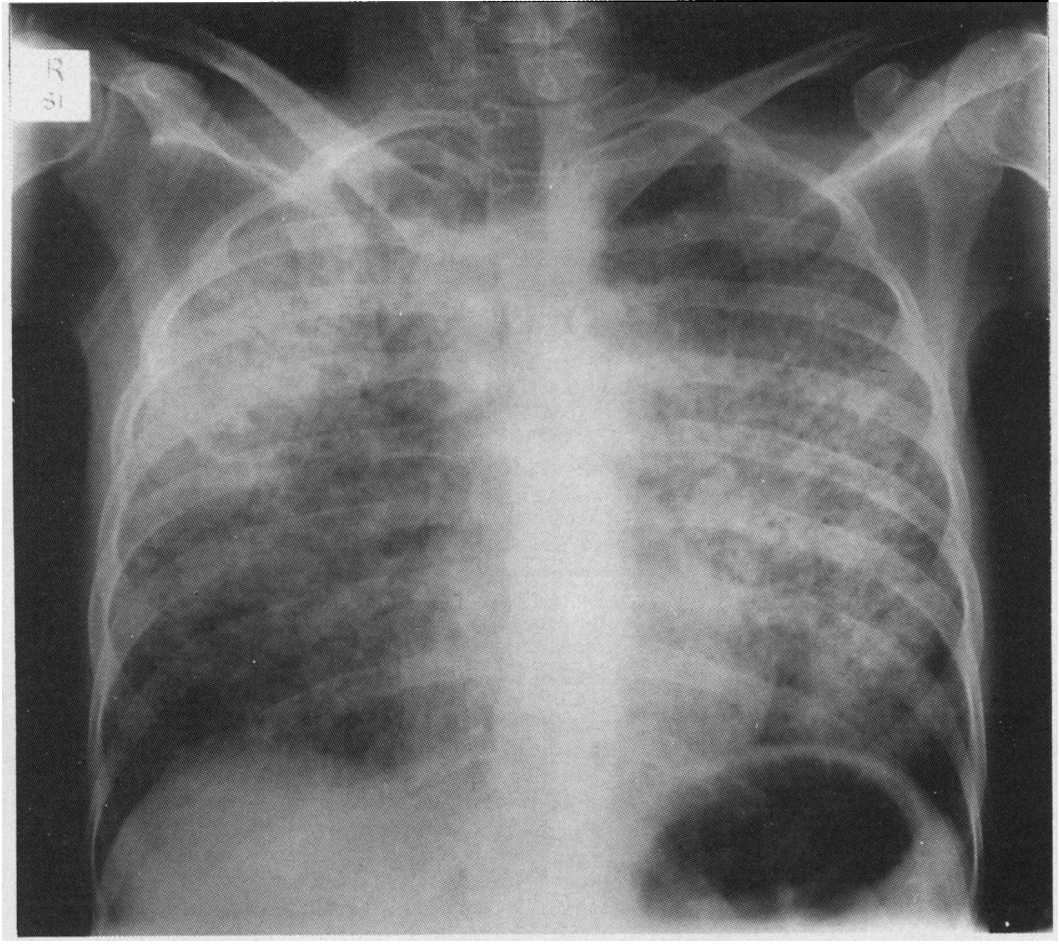

Patient 1: Chest radiograph showing widespread interstitial shadowing.

malaise, and a rash, which had lasted until his admission.

\section{CASE 2}

A 37 year old man, who had had an allogeneic cadaveric renal transplant in 1984 for chronic renal failure secondary to proliferative glomerulonephritis, presented in November 1990 with a three week history of malaise, fever, dry cough, and increasing exertional dyspnoea. At the time he was taking prednisolone $10 \mathrm{mg}$ and azathioprine $50 \mathrm{mg}$ daily. Chest radiography showed bilateral early interstitial shadowing; percutaneous capillary oxygen saturation values fell from $97 \%$ at rest to $92 \%$ after exercise. Twelve hours after diagnostic bronchoalveolar lavage he became hypotensive, his oxygen saturation fell to $88 \%$, and he required nasal intermittent positive pressure ventilation. ${ }^{8} \mathrm{He}$ was started on high dose cotrimoxazole and ganciclovir (adjusted for renal function) pending results of bronchoalveolar lavage, and six doses of intravenous immunoglobulin $(30 \mathrm{~g}$ ) and $20 \mathrm{mg}$ oral prednisolone a day. His condition improved and ventilation was withdrawn after 48 hours. Cytomegalovirus was the only agent identified in the bronchoalveolar lavage sample and, on screening, cytomegalovirus retinitis was identified in the right eye. HIV-1 antibodies, hepatitis B surface antigen, and hepatitis $B$ e antigen were detected in serum. The patient said that the only occasion he had been at risk of acquiring HIV was three months before his admission. He was discharged from hospital after three weeks of co-trimoxazole treatment. Zidovudine $500 \mathrm{mg}$ daily in divided doses and nebulised pentamidine prophylaxis $(300 \mathrm{mg}$ fortnightly) were introduced. While he was in hospital azathioprine had been discontinued and the prednisolone dose reduced to $10 \mathrm{mg}$ daily. Two months after he had been admitted he returned to full time employment (CD4 count $\left.0.52 \times 10^{9} / 1\right)$ and at four months he remains well $\left(\mathrm{CD} 4\right.$ count $\left.0.46 \times 10^{9} / 1\right)$. HIV-1 antibodies and hepatitis B surface antigen were not detected in stored serum from the time of transplantation.

\section{Discussion}

The relative contribution of each organism to the clinical presentation cannot always be ascertained when several infectious agents are identified at bronchoalveolar lavage. This study has therefore examined the nine episodes where cytomegalovirus was the only agent identified at bronchoalveolar lavage. In these nine episodes severe pneumonitis occurred in the two patients with the highest peripheral blood CD4 counts $\left(>0.2 \times 10^{9} / 1\right)$. Recent reports have shown how unusual serious opportunist infections are in patients with CD4 counts in this range ${ }^{910}$; possibly our two patients had CD4 counts of this order because they were experiencing HIV seroconversion syndromes complicated by opportunist infection. Although cases of oesophageal candidiasis complicating HIV seroconversion have been described, ${ }^{11}$ cases of Pneumocystis carinii or cytomegalovirus pneumonitis in a similar context have not. We have no proof of the timing of HIV seroconversion in either case, but the increases in CD4 counts following the episodes are suggestive. Zidovudine treatment is unlikely to have been the sole factor in these improvements in CD4 counts. Features in the history of both cases suggest recent acquisition of HIV and possibly patient 2 acquired HIV along with hepatitis $B$ virus. With unusually high CD4 counts at presentation and later rises, both patients may have had greater potential for cell mediated immune responses to cytomegalovirus within the lungs. Immune responses may therefore have been responsible for the severity of pneumonitis in both cases.

The seven patients with cytomegalovirus pneumonitis and CD4 counts below $0.1 \times 10^{9} / 1$ did not receive antipneumocystis treatment and respiratory symptoms resolved spontaneously. The two patients requiring ventilation because of the severity of the respiratory episodes, however, were treated with high dose co-trimoxazole in addition to anticytomegalovirus drugs for 28 and 21 days despite the failure to detect $P$ carinii. This raises the possibility therefore that part of their clinical response could be attributed to the treatment of pneumocystis infection that we had failed to detect by bronchoalveolar lavage and cytology. Indeed, our rate of detection of $P$ carinii of $34 \%$ (29/85 respiratory episodes) is somewhat lower than the rates in the region of $50 \%$ found in other bronchoalveolar lavage series. ${ }^{12-14}$ These series, however, date from before widespread introduction of prophylaxis against Pneumocystis carinii and our patients were receiving nebulised pentamidine prophylaxis (as described $^{15}$ ) at the time of bronchoalveolar lavage in half $(42 / 85)$ of the respiratory episodes. We 
believe, but cannot prove, that our lower rate of detection of $P$ carinii was a result of the efficacy of this prophylaxis rather than a failure of detection. Sensitivities of around $90 \%$ have been quoted for the detection of $P$ carinii in HIV infected patients from bronchoalveolar lavage with cytology ${ }^{1213}$ and even where blind bronchial washings are made the sensitivity is of the order of $80 \%{ }^{16}$ True sensitivity rates for bronchoalveolar lavage with cytology have, however, been difficult to establish in the absence of a "gold standard" for the diagnosis of pneumocystis pneumonia and may be higher than $90 \%$ in some series. Nevertheless, some so called high dose co-trimoxazole responders for whom bronchoalveolar lavage and conventional cytology had failed to detect $P$ carinii have given positive results for this organism with DNA amplification. ${ }^{17}$ There is therefore a small possibility that undiagnosed $P$ carinii infection may have contributed to the clinical course in case 2 . In case 1 , however, this is unlikely in view of the response to high dose cotrimoxazole in the episode immediately before that attributed to cytomegalovirus as well as the fact that $P$ carinii was not identified by repeated bronchoalveolar lavage during the period of ventilation.

In view of the doubts about the significance of culturing cytomegalovirus from bronchoalveolar lavage fluid in patients infected with HIV it has been suggested that cytomegalovirus should be considered as contributing to the pathological process only when viral inclusion bodies, identified histologically or cytologically, provide evidence of "invasive disease." ${ }^{18}$ This suggestion is not supported by our study, where viral inclusion bodies were seen in bronchoalveolar lavage cells in both the severe and the mild respiratory episodes attributed to cytomegalovirus alone (table 3 ). The cytomegalovirus identified at bronchoalveolar lavage in either of the two severe cases is unlikely to have been a contaminant from saliva or due to cytomegalovirus viraemia as the virus was not detected in saliva or blood taken at time of bronchoalveolar lavage in either case (table 3).

This study lends support to the hypothesis that severe cytomegalovirus pneumonitis in immunocompromised patients requires some capacity for a cell mediated immune response in the lungs, which is absent in most patients with AIDS. Further studies of immune responses within the lungs of these patients are needed to confirm this.
S B S is supported by a Wellcome Trust medical graduate training fellowship.

1 Grundy JE, Shanley JD, Griffiths PD. Is cytomegalovirus pneumonitis in allogeneic transplant recipients an immunopathological condition? Lancet 1987;ii:996-9.

2 Millar AB, Patou G, Miller RF, Grundy JE, Katz DR, Weller IV, et al. Cytomegalovirus in the lungs of patients with AIDS: respiratory pathogen or passenger? $\mathrm{Am} \mathrm{Rev}$ Respir Dis 1990;141:1474-7.

3 Jacobsen MA, Mills J, Rush J, Peiperl L, Seru V, Prasanna $\mathrm{KM}$, et al. Morbidity and mortality of patients with AIDS and first-episode Pneumocystis carinii pneumonia unaffected by concomitant pulmonary cytomegalovirus infection. Am Rev Respir Dis 1991;144:6-9.

4 Bower M, Barton SE, Nelson MR, Bobby J, Smith D, Youle $M$. The significance of the detection of cytomegalovirus in the bronchoalveolar lavage fluid in AIDS patients with pneumonia. AIDS 1990;4:317-20.

5 Miles PR, Baughman RP, Linneman CC. Cytomegalovirus in the bronchoalveolar lavage fluid of patients with AIDS. Chest 1990;97:1072-6.

6 Griffiths PD, Panjwani DD, Stirk PR, Ball MG, Ganczakowski M, Blacklock HA, et al. Rapid diagnosis of cytomegalovirus infection in immunocompromised patients by detection of early antigen fluorescent foci. Lancet 1984;ii:1242-5.

7 Phillips AN, Lee CA, Elford J, Janossy G, Timms A, Bofill $M$, et al. Serial CD4 lymphocyte counts and development of AIDS. Lancet 1991;337:389-92.

8 Elliott MW, Steven MH, Phillips GD, Branthwaite MA. Non-invasive mechanical ventilation for acute respiratory failure. $B M J$ 1990;300:358-60.

9 Crowe S, Stewart K, Carlin J, Hoy JF. Relationship between opportunistic infections (OI) and malignancy $(\mathrm{OM})$ in HIV patients and CD4 lymphocyte number [abstract]. Sixth International Conference on AIDS. San Francisco: Sixth Internatio
1990:SB526.

10 Masur H, Ognibene FP, Yarchoan R, Shelhamer JH, Baird $\mathrm{BF}, \mathrm{Travis} \mathrm{W}$, et al. CD4 counts as predictors of opportunistic pneumonias in human immunodeficiency virus (HIV) infection. Ann Intern Med 1989;111:223-31.

11 Pedersen C, Gerstoft J, Lindhart BO, Sindry J. Candida oesophagitis associated with acute human immunodeficiency virus infection. $J$ Infect Dis 1987;156:529-30.

12 Griffiths MR, Kocjan G, Miller RF, Godfrey-Faussett P. Diagnosis of pulmonary disease in human immunodeficiency virus infection: role of transbronchial biopsy and bronchoalveolar lavage. Thorax 1989;44:554-8.

13 Broaddus C, Dake MD, Stulbarg MS. Bronchoalveolar lavage and transbronchial biopsy for the diagnosis of pulmonary infections in the acquired immunodeficiency syndrome. Ann Intern Med 1985;102:747-52.

14 Barrio JL, Harcup C, Baier HJ, Pitchenik AE. Value of repeat fiberoptic bronchoscopies and significance of nondiagnostic bronchoscopic results in patients with the acquired immunodeficiency syndrome. Am Rev Respir Dis acquired immunode

15 Simonds AK, Newman SP, Johnson MA, Talaee N, Lee CA, Clarke SW. Simple nebuliser modification to enhance alveolar deposition of pentamidine. Lancet 1989;ii:953.

16 Martin WR, Albertson TE, Siegel B. Tracheal catheters in patients with acquired immunodeficiency syndrome for the diagnosis of Pneumocystis carinii pneumonia. Chest 1990;98:29-32.

17 Wakefield AE, Pixley FJ, Banerji S, Sinclair K, Miller RF, Moxon ER, et al. Detection of Pneumocystis carinii with DNA amplification. Lancet 1990;336:451-3.

18 Communicable Diseases Center. Revision of the CDC surveillance case definition for acquired immunodeficiency syndrome. Mortality and Morbidity Weekly Reports 1987; 36:1-15S. 